\title{
KONDISI EKOSISTEM MANGROVE DI KAWASAN EKOWISATA KARANGSONG KABUPATEN INDRAMAYU
}

\author{
Aulia Rosdiana Tufliha ${ }^{1}$ Daffa Manggala Putra ${ }^{1}$ Delima Mentari Amara ${ }^{1}$ Ressa Muhammad Santika ${ }^{1}$ \\ Sandra Moerti Oktavian ${ }^{1}$ Perdana Putra Kelana ${ }^{1,2}$ \\ ${ }^{1}$ PARIMANTA FPIK UNPAD (Observant and Scientific Explorer Organization) \\ Gedung Cekdam Komplek UKM Barat Unpad Jl. Raya Bandung-Sumedang KM. 21 Jatinangor, \\ ${ }^{2}$ Dosen Politeknik Kelautan dan Perikanan Dumai \\ Jl. Wan Amir No.1 Pangkalan Sesai, Dumai Barat, Kota Dumai, Riau, 28824 \\ Email Korespondensi: Parimanta@msn.com
}

\begin{abstract}
ABSTRAK
Ekosistem mangrove di Kawasan Ekowisata Karangsong Kabupaten Indramayu merupakan salah satu wilayah rehabilitasi mangrove. Penelitian dilaksanakan pada bulan Agustus 2018 di Kawasan Ekowisata Karangsong Kabupaten Indramayu guna mengetahui kondisis ekosistem mangrove dengan menggunakan metode Transek Line Plot (TLP). Stasiun pengamatan diambil berdasarkan waktu rehabilitasi dan keterwakilan wilayah pada bagian selatan, bagian tengah dan bagian utara kawasan ekowisata mangrove Karangsong. Berdasarkan hasil penelitian, terdapat dua jenis mangrove yaitu Avicennia marina dan Rhizophora mucronata. Kerapatan pada tingkat pohon di ekosistem mangrove Karangsong termasuk kedalam kategori rusak, tetapi menuju perkembangan kearah yang lebih baik ditunjukan dengan nilai kerapatan yang tinggi pada tingkat pancang dan semai. Parameter kualitas air seperti suhu, salinitas dan $\mathrm{pH}$ perairan serta jenis substrat berlumpur mendukung untuk pertumbuhan mangrove.
\end{abstract}

Kata Kunci: Ekosistem, Indramayu, Kondisi, Mangrove dan Vegetasi

\section{CONDITION OF MANGROVE ECOSYSTEM IN KARANGSONG ECOTOURISM INDRAMAYU DISTRICT}

\begin{abstract}
Mangrove ecosystem in Karangsong ecotourism area, Indramayu District is a mangrove rehabilitation area. The research was conducted on August 2018 in the Karangsong Ecotourism Area of Indramayu District to determine the condition of the mangrove ecosystem. The research station was chosen based on the plantation ages and representation of the southern, central and northern parts of the Karangsong mangrove ecotourism area. Transect Line Plot were used to determaine mangrove condition. According to the research there were only two species of mangrove, Avicennia marina and Rhizophora mucronata. The density of mangrove was broken category but had regeneration shown by high density of mangrove seeds. The water quality parameters such as temperature, salinity $\mathrm{pH}$ and muddy substrates that can be tolerated for mangrove growth.
\end{abstract}

Key Words: Ecosystem, Indramayu, Condition, Mangrove and Vegetation

\section{PENDAHULUAN}

Ekosistem mangrove merupakan ekosistem yang dominan di wilayah pesisir di daerah ekuator (Adame dan Catherine, 2010). Ekosistem ini memiliki fungsi ekologis dan ekonomis yang sangat penting. Secara ekologis, ekosistem mangrove berfungsi sebagai daerah pemijahan (spawning grounds) dan daerah pembesaran (nursery grounds) berbagai biota perairan, selain itu serasah mangrove (berupa daun dan ranting) yang jatuh akan menjadi sumber pakan dalam lingkungan perairan setelah melalui proses dekomposisi (Wantasen, 2013). Fungsi ekonomis ekosistem mangrove saat ini banyak dimanfaatkan untuk menjadi daerah ekowisata yang dapat meningkatkan pendapatan masyarakat dan menggerakan roda ekonomi wilayah sekitar (Prihadi dkk, 2018).
Laju pembangunan khususnya di wilayah pesisir semakin tinggi, hal tersebut diiringi dengan meningkatnya pemanfaatan sumberdaya alam dan perubahan terhadap lingkungan hidup (Lalo, 2003). Di wilayah pesisir Karangsong Kabupaten Indramayu, ekosisten mangrove mengalami tekanan yang besar. Alih fungsi lahan menjadi tambak menyebabkan ekosistem mangrove menjadi terganggu. Hal tersebut dibuktikan dengan berkurangnya jenis mangrove yang ada dan diperkirakan dalam 30 tahun kedepan akan terjadi abrasi yang dapat menyebabkan mundurnya garis pantai ke daerah daratan sepanjang $1 \mathrm{~km}$ (Petra dkk, 2012).

Sejak tahun 2008, masyarakat Karangsong melalui Kelompok Tani Pantai Lestari menyadari akan dampak buruk dari alih fungsi ekosistem mangrove. Kelompok ini melakukan rehabilitasi mangrove dengan cara menanam mangrove secara 
bertahap di Muara Sungai Song. Hingga saat ini Kelompok Tani Pantai Lestari sudah berhasil membentuk kawasan rehabilitasi mangrove seluas 15 hektar yang membentang disepanjang pesisir pantai Desa Karangsong hingga Muara Suangai Song. Kelompok masyarakat ini berupaya untuk mengembalikan peran dan fungsi ekologis mangrove agar dapat dimanfaatkan sebagai kawasan ekowisata mangrove yang dapat bermanfaat secara langsung terhadap perekonomian masyarakat (Prayudha dkk, 2014). Kelompok Tani Pantai Lestari memiliki hambatan dalam pengembangan kawasan ekowisata, diantaranya adalah kurangnya informasi dan kajian ilmiah yang membahas mengenai kondisi ekosistem mangrove secara terukur. Berdasarkan hal tersebut maka perlu dilakukan kajian ilmiah yang bertujuan untuk mengetahui kondisi ekosistem mangrove di wilayah ekowisata Karangsong Kabupaten Indramayu.

\section{METODE}

\section{Lokasi dan Waktu}

Penelitian dilakukan di kawasan Ekowisata Mangrove Karangsong Kabupaten Indramayu Jawa Barat pada bulan Agustus 2018. Lokasi pengambilan data dibagi menjadi tiga stasiun berdasarkan waktu rehabilitasi dan keterwakilan wilayah pada Kawasan Ekowisata Mangrove Karangsong. Stasiun satu merupakan lokasi tahap satu rehabilitasi dan berada pada wilayah paling timur serta berbatasan dengan Muara Song, stasiun dua merupakan lokasi tahap dua rehabilitasi dan berada di bagian tengah kawasan, serta stasiun tiga merupakan tahap tiga rehabilitasi dan berada pada wilayah paling barat serta berbatasan dengan arboretum mangrove. Lokasi penelitian dapat dilihat pada Gambar 1.

\section{Alat dan Bahan}

Peralatan yang digunakan dalam penelitian ini terbagi menjadi tiga. Pertama adalah peralatan yang digunakan untuk pengambilan data kondisi mangrove, seperti roll meter dan tali raffia untuk membuat transek, meteran jahit untuk mengukur lingkar batang mangrove, Global Positioning System (GPS) untuk mencatat lokasi sampling, survey sheet, papan dada dan alat tulis untuk mencatat hasil survey serta Buku Panduan Mangrove Indonesia Kittamura (2003). Kedua adalah peralatan untuk mengukur kualitas air, diantaranya adalah Thermometer untuk mengukura suhu, Refraktrometer untuk mengukur salinitas dan $\mathrm{pH}$ meter untuk megukura kadar $\mathrm{pH}$ pada perairan ekosistem mangrove. Peralatan yang ketiga digunakan untuk pengamatan substrat, diantaranya adalah skop untuk mencuplik contoh substrat, plastik zipper untuk menyimpanan contoh substrat dan Comparator sediment untuk mengetahui jenis substrat.

\section{Metode Pengambilan Data}

Pengambilan data kondisi ekosistem mangrove dilakukan dengan menggunakan metode Transect Line Plot (TLP). Garis transek ditarik tegak lurus dari laut menuju darat. Data vegetasi mangrove dicuplik menggunakan petak berukuaran 10x10 m untuk kategori pohon (diameter >10 cm), 5x5 m untuk kelompok pancang (diameter 2-10 cm), dan $1 \mathrm{x} 1 \mathrm{~m}$ untuk kelompok semai (diameter $<2 \mathrm{~cm}$ ) (SNI, 2011). Pengukuran kualitas air dan pengambilan contoh sedimen menggunakan metode grab sampling. Parameter kualitas air yang diukur adalah suhu, salinitas dan $\mathrm{pH}$. Pengukuran parameter kualitas air dilakukan secara insitu. Contoh sedimen diambil menggunakan skop kemudian dimasukan kedalam plastik zipper yang sudah diberi label sesuai dengan stasiun pengambilan contoh. Contoh sedimen tersebut kemudian dibawa dan dibandingkan dengan komparator sediment untuk mengetahui jenisnya.

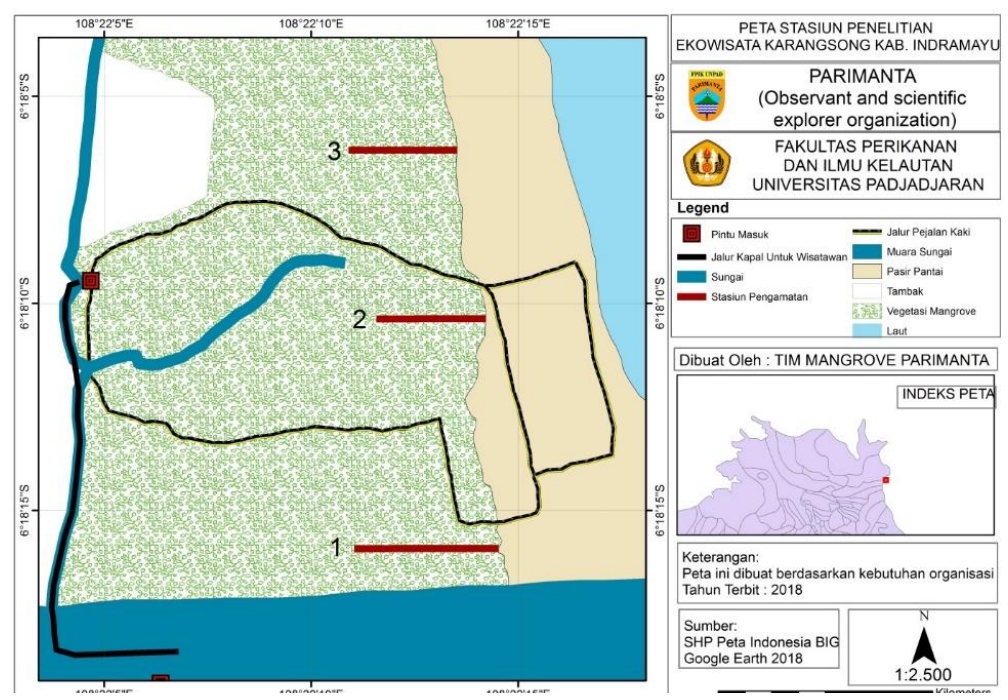

Gambar 1. Peta Lokasi Penelitian 


\section{Analisis Data}

Kondisi ekosistem mangrove dapat dianalisis dengan mengetahui Indeks Nilai Penting (INP). Menurut English dkk (1994), nilai penting suatu jenis didapat dengan menggunakan persamaan sebagai berikut:

$$
I N P=K R i+F R i+D R i
$$

Nilai penting suatu jenis berkisar antara 0 hingga 300. Nilai penting memberikan suatu gambaran mengenai pengaruh atau peranan suatu jenis mangrove dalam komunitas. INP merupakan penjumlahan dari nilai kerapatan relatif jenis (KRi), frekuensi relatif jenis (FRi) dan Dominansi relatif jenis (DRi). Nilai-nilai tersebut diperoleh dengan menggunakan persamaan sebagai berikut:

(a) Kerapatan jenis (Ki) merupakan jumlah tegakan jenis i (ni) dalam satuan unit area yang diukur (A)

$$
K i=\frac{n i}{A}
$$

(b) Kerapatan relatif jenis i (KRi) merupakan perbandingan antara tegakan jenis $\mathrm{i}(\mathrm{ni})$ dengan jumlah total tegakan seluruh jenis $\left(\sum n\right)$

$$
K R i=\frac{n i}{\sum n} \times 100
$$

(c) Frekuensi jenis (Fi) merupakan jumlah petak contoh atau plot yang ditemukan suatu jenis (pi) dalam jumlah keseluruhan petak contoh atau plot yang diamati $\left(\sum p\right)$

$$
F i=\frac{p i}{\sum p}
$$

(d) Frekuensi relatif jenis (Fri) merupakan perbandingan antara frekuensi jenis i (Fi) dengan jumlah frekuensi untuk seluruh jenis $\left(\sum f\right)$

$$
F R i=\frac{F i}{\sum f} \times 100
$$

(e) Dominasi jenis (Di) merupakan luas bidang dasar jenis $\mathrm{i}(\mathrm{Li})$ dalam suatu unit area

$$
D i=\frac{L i}{A}
$$

Keterangan: $\mathrm{Li}$ atau BA (basal Area) = $\pi \mathrm{DBH}^{2} / 4$ (dalam $\mathrm{cm}^{2}$ ), $\mathrm{DBH}$ merupakan diameter pohon dari jenis kei $\mathrm{I}$, dimana $\mathrm{DBH}=$ $\mathrm{CBH} / \pi$ (dalam $\mathrm{cm}$ ); $\mathrm{CBH}$ merupakan lingkar pohon setinggi dada; $\pi$ (3.1416) adalah konstanta.

(f) Dominasi relatif jenis (DRi) perbandingan antara dominasi jenis I dan dominasi seluruh jenis

$$
D R i=\frac{D i}{\sum D} \times 100
$$

Analisis Kondisi ekosistem mangrove dan hasil pengukuran kualitas air serta substrat dibahas secara deskriptif. Analisis deskriptif bertujuan untuk memahami fenomena yang ada, upaya menjaring informasi secara mendalam dari permasalahan yang ada dalam suatu kajian, dihubungkan dengan pemecahan suatu masalah, baik dari sudut pandang teoritis maupun empiris.

\section{HASIL DAN PEMBAHASAN}

\section{Vegetasi Mangrove}

Jenis mangrove yang ditemukan pada lokasi penelitian Kawasan Ekowisata Mangrove Karangsong sebanyak 2 jenis, yaitu Avicennia marina dan Rhizophora mucronata. Jenis Avicennia marina ditemukan pada seluruh stasiun, sedangkan jenis Rhizophora mucronata hanya ditemukan pada stasiun 2. Distribusi jenis mangrove tersaji pada tabel 1. Jenis mangrove yang ditemukan cenderung sama, karena lokasi penelitian merupakan daerah rehabilitasi. Rehabilitasi mangrove dapat mempengaruhi distribusi mangrove (Jusoff, 2013). Rehabilitasi yang dilakukan di lokasi penelitian berupa penanaman jenis Avicennia marina. Avicennia marina merupakan mangrove pionir yang baik untuk ditanam pada daerah rehabilitasi (Husnaeni, 2013).

Tabel 1. Distribusi Jenis Mangrove pada Lokasi Penelitian

\begin{tabular}{llccc}
\hline \multicolumn{5}{c}{ Penelitian } \\
\hline No & Jenis Mangrove & St 1 & St 2 & St 3 \\
\hline $1 \quad$ Avicennia marina & + & + & + \\
2 & Rhizophora mucronata & - & + & - \\
\hline Jumlah Jenis yang & 1 & 2 & 1 \\
ditemukan & & & \\
\hline
\end{tabular}

Pengukuran vegetasi mangrove menggunkana 3 kategori yaitu pohon, pancang dan semai (English dkk, 1994). Berdasarkan hasil penelelitian hanya terdapat 1 jenis mangrove kategori pohon yaitu Avicennia marina yang terdapat di Kawasan Ekowisata Mangrove Karangsong Kabupaten Indramayu. Avicennia marina terdapat diseluruh stasiun dengan kerapatan sebesar 633 ind/ha pada stasiun 1, $366 \mathrm{ind} /$ ha pada stasiun 2 dan $100 \mathrm{ind} / \mathrm{ha}$ pada stasiun 3 (Tabel 2). Kerapatan mangrove kategori pohon termasuk dalam kriteria kerapatan jarang berdasarkan Keputusan Menteri Lingkungan Hidup Nomor 201 Tahun 2004 Tentang Kriteria Baku dan Pedoman Penentuan Kerusakan Mangrove.

Kerapatan pada Kategori Pancang tertinggi terdapat pada stasiun 1 dengan nilai 8533 ind/ha. Pada stasiun 2 terdapat 2 jenis pancang yaitu Avicennia marina dan Rhizophora mucronata yang masing-masing memiliki nilai kerapatan 400 ind/ha dan 4666 ind/ha. Kerapatan pada tingkat semai teritinggi terdapat pada stasiun 2 dengan nilai 
Tabel 2. Kerapatan Mangrove Pada Lokasi Penelitian

\begin{tabular}{ccccc}
\hline \multirow{2}{*}{ Stasiun } & \multirow{2}{*}{ Jenis Mangrove } & \multicolumn{3}{c}{ Kerapatan (ind/ha) } \\
\cline { 3 - 5 } & Avicenia marina & Pohon & Pancang & Semai \\
\hline 1 & Total Kerapatan & $\mathbf{6 3 3}$ & $\mathbf{8 5 3 3}$ & $\mathbf{1 0 0 0 0}$ \\
\hline \multirow{2}{*}{2} & Avicenia marina & 366 & 400 & 260000 \\
& Rhizophora mucronata & - & 4666 & - \\
\hline 3 & Total Kerapatan & $\mathbf{3 6 6}$ & $\mathbf{5 0 6 6}$ & $\mathbf{2 6 0 0 0 0}$ \\
\hline \multirow{2}{*}{3} & Avicenia marina & 100 & 4533 & 126666 \\
\hline & Total Kerapatan & $\mathbf{1 0 0}$ & $\mathbf{4 5 3 3}$ & $\mathbf{1 2 6 6 6 6}$
\end{tabular}

$260000 \mathrm{ind} / \mathrm{ha}$. Tingginya nilai kerapatan pada tingkat pancang dan semai kemampuan regenerasi mangrove pada stasiun tersebut masih baik (Kelana dkk, 2015). Menurut Nursal (2005) tingkat regenerasi mangrove yang baik ditunjukan dengan kerapatan jenis pada tingkat pancang lebih dari 240 ind/ha dan pada tingkat semai lebih dari $1000 \mathrm{ind} / \mathrm{ha}$

INP merupakan gambaran keterwakilan jenis mangrove yang berperan dalam ekosistem (Jesus, 2012). INP disajikan pada table 3 . Hasil perhitungan menunjukan bahwa jenis Avicennia marina pada kategori pohon memiliki nilai sempurna pada seluruh stasiun. Avicennia marina merupakan jenis mangrove pionir yang digunakan untuk rehabilitasi dan biasanya terdapat pada bagian terdepan atau terdekat dengan laut pada ekosistem mangrove (Natividad $\mathrm{dkk}$, 2015). Jenis mangrove dari genus avicennia memiliki korelasi yang erat dengan substrat berlumpur (Fadli, 2015). Berdasarkan hal tersebut Avicennia marina merupakan jenis mangrove yang paling berperan di Kawasan Ekowisata mangrove Karangsong. INP Avicennia marina kategori pancang dan semai pada stasiun 1 dan 3 memiliki nilai sempurna, hal tersebut dikarenakan pada stasiun tersebut merupakan lokasi rehabilitasi mangrove. INP Avicennia marina kateogri pancang di stasiun memiliki nilai lebih kecil dibandingkan dengan
Rhizophora mucronata. Jenis Rhizophora mucronata sudah berada dikawasan tersebut sebelum rehabilitasi mangrove dilakukan. Genus rhizophora dapat tumbuh dan berkembang dengan baik pada substrat berlumpur (Anwar dan Mertha, 2017).

\section{Parameter Lingkungan}

Tabel 4 menunjukan hasil pengukuran parameter kualitas air dan tipe substrat pada lokasi penelitian. Suhu air pada lokasi penelitian berkisar $26-27^{\circ} \mathrm{C}$. Menurut Haya dkk (2015) suhu optimum bagi ekosistem mangrove untuk tumbuh dan fotosintesis berkisar antara $25-35^{\circ} \mathrm{C}$. Suhu dapat mempengaruhi konduktansi stomata dan laju asimilasi pada daun mangrove pada kisaran suhu yang optimum dan akan mengalami penurunan yang cepat pada suhu di atas $35{ }^{\circ} \mathrm{C}$. Suhu perairan juga dapat mempengaruhi sebaran mangrove jenis Rhizophora mucronata (Poedjirahajoe dkk, 2017). Suhu perairan yang cukup rendah disebabkan oleh tutupan kanopi yang cukup lebat sehingga intensitas cahaya matahari yang sampai ke badan perairan cukup rendah. Perbedaan kisaran suhu perairan pada stasiun pengamatan dapat disebabkan oleh arus air, penutupan kanopi vegetasi, dan kondisi diwilayah pengamatan (Jesus, 2011).

Tabel 3. Indeks Nilai Penting Mangrove pada Lokasi Penelitian

\begin{tabular}{|c|c|c|c|c|}
\hline \multirow{2}{*}{ Stasiun } & \multirow{2}{*}{ Jenis Mangrove } & \multicolumn{3}{|c|}{ INP (\%) } \\
\hline & & Pohon & Pancang & Semai \\
\hline \multirow[t]{2}{*}{1} & Avicenia marina & 300 & 200 & 200 \\
\hline & Total Kerapatan & 300 & 200 & 200 \\
\hline \multirow[t]{3}{*}{2} & Avicenia marina & 300 & 41 & 200 \\
\hline & Rhizophora mucronata & - & 159 & - \\
\hline & Total Kerapatan & 300 & 200 & 200 \\
\hline \multirow[t]{2}{*}{3} & Avicenia marina & 300 & 200 & 200 \\
\hline & Total Kerapatan & 300 & 200 & 200 \\
\hline
\end{tabular}


Tabel 4. Parameter Kualitas Air dan Lingkungan pada Lokasi Penelitian

\begin{tabular}{|c|c|c|c|c|}
\hline \multirow{2}{*}{ Parameter } & \multirow{2}{*}{ Satuan } & \multicolumn{3}{|c|}{ Stasiun } \\
\hline & & 1 & 2 & 3 \\
\hline \multicolumn{5}{|l|}{ Air } \\
\hline Suhu & ${ }^{\circ} \mathrm{C}$ & 26 & 26 & 27 \\
\hline Salinitas & PPT & 24 & 26 & 28 \\
\hline $\mathrm{pH}$ & - & 6,97 & 7,14 & 6,67 \\
\hline \multicolumn{5}{|l|}{ Substrat } \\
\hline Tipe Substrat & - & Berlumpur & Berlumpur & Berlumpur \\
\hline
\end{tabular}

Salinitas pada lokasi penelitian berkisar antara 24-28 PPT. stasiun 1 memiliki nilai salinitas terendah karena lokasinya berdekatan dengan muara sungai yang masih dipengaruhi air tawar. Salinitas dipengaruhi oleh pasang surut, curah hujan, penguapan, presipitasi dan topografi suatu perairan, akibatnya salinitas suatu perairan dapat sama atau berbeda dengan perairan lainnya. Gerakan pasang surut selain berpengaruh terhadap nilai salinitas, juga dapat berperan dalam penyebaran biji, daya tumbuh biji sehingga dapat memunculkan zonasi Pramudji (2000). Genus Avicennia memiliki kemampuan kisaran toleransi yang tinggi dibandingkan dengan genus lainnya. Avicenia marina mampu tumbuh pada salinitas mendekati 0-90 PPT (Mughofar, 2018). Pada stasiun 2 dengan nilai salinitas 26, ditemukan genus Avicennia dan Rhizophora. Menurut Pramudji (2000) Genus Avicenia biasanya berasosiasi dengan genus Rhizhopora.

Nilai $\mathrm{pH}$ pada saat pengamatan berkisar antara 6,67-7,14. Kisaran $\mathrm{pH}$ tersebut relatif netral dan dapat mendukung pertumbuhan mangrove. Menurut Prihadi dkk (2018) hutan mangrove Karangsong memiliki $\mathrm{pH}$ relatif netra. Nilia $\mathrm{pH}$ yang baik untuk mangrove berkisar 6,5-8,5. Nilai $\mathrm{pH}$ dapat mempengaruhi proses biokimia perairan yang berdampak kepada pertumbuhan dan kerapatan jenis mangrove secara alami (Susiana, 2017). Stasiun 2 dengan $\mathrm{pH}$ tertinggi memiliki tegakan Rhizophora mucronate pada kategori pancang yang tumbuh secara alami dengan kerapatan 4666 ind/ha. Berbeda dengan stasiun 1 dan stasiun 3 yang mangrovenya merupakan hasil rehabilitasi dengan cara penanaman.

Substrat merupakan bagian penting dari ekosistem mangrove. Substrat dapat mempengaruhi penyebaran, bentuk perakaran dan kandungan bahan organik yang akan dimanfaatkan oleh mangrove (Kelana dkk, 2015). Lokasi penelitian memiliki tipe substrat berlumpur. Tipe substrat berlumpur merupakan substrat yang baik bagi genus Avicennia dan Rhizophora. Hal tersebut sesuai dengan pernyataan fadli (2015) bahwa jenis mangrove dari genus avicennia memiliki korelasi yang erat dengan substrat berlumpur. Rhizophora mucronate merupakan jenis mangrove yang dapat tumbuh dengan baik pada substrat yang berupa lumpur tebal (Usman dkk, 2013).

\section{SIMPULAN}

Berdasarkan kategori pohon, kondisi ekosistem mangrove pada lokasi penelitian termasuk dalam kriteria rusak atau jarang karena memiliki nilai kerapatan kurang 1000 ind/ha, tetapi kerapatan pada kategori pancang dan semai berda pada kondisi yang baik karena berada diatas 240 ind/ha dan 10000 ind/ha. Hal tersebut menggambarkan bahwa rehabilitasi mangrove dengan melakukan penanaman cukup berhasil karena memiliki tingkat regenerasi yang baik ditandai dengan tingginya nilai kerapatan pancang dan semai. Jenis Avicenia marina merupakan jenis ang ditanam untuk rehabilitasi dan paling berperan dalam ekosistem tersebut, hal ini digambarkan dengan nilai INP yang sempurna. Kondisi kualitas perairan dan substrat dalam kategori baik untuk pertumbuhan mangrove.

\section{UCAPAN TERIMAKASIH}

Penulis mengucapkan terimkasih kepada Dewan Pengurus PARIMANTA yang telah mendukung dan memfasiltasi kegitan ini. Penulis juga sampaikan rasa terimkasih kepada FPIK Unpad dan masyarakat Karangsong serta pihak-pihak lain yang telah membantu dalam pelaksanaan riset dan penyelesaian tulisan ini.

\section{DAFTAR PUSTAKA}

Adame, M.f., Chatherin, E.L. 2011. Carbon and nutrient exchange of mangrove forest with the coastal ocean. Hydrobiologia. 663:23-50.

Anwar, H., dan Mertha. I.G. 2017. Komposisi jenis mangrove di Teluk Gerupuk Kabupaten Lombok Tengah. Jurnal Sangkareang Mataram. 3(2):25-30. 
English, S.C., Wilkinson, dan Baker, V. 1994. Survey Manual for Tropical Marine Resources. [AIMS] Australian Marine Institute of Marine Science. Townsville (AU). 119-196.

Fadli, Kharijon, dan Sofiyanti, N. 2015. Analisis vegetasi Avicennia sp dan karakteristik sedimen di kawasan mangrove Desa Sungai Rawa Kecamatan Sungai Apit Kabupaten Riau. JOM. 2(1):23-34.

Haya, N., Zamani, N.P., dan Soedharma, D. 2015. Analisis struktur ekosistem mangrove di Desa Kukupang Kecamatan Kepulauan Joronga. Jurnal Teknologi Perikanan dan Kelautan. 6(1):79-89

Husnaeni, A. 2013. Pertumbuhan anakan Avicennia marina dan Rhisophora mucronata pada jarak tanam yang berbeda dengan menggunakan teknik penanaman guludan [Tesis]. Bogor. Institut Pertanian Bogor.

Jesus, A. 2012. Kondisi ekosistem mangrove di Sub District Liquisa Timor-Leste. Depik. 1(3):136-143.

Jusoff, K. 2013. Malaysian mangrove and their Siginificance to the coastal marine environment. Polish Journal of Environmental Studies. 22(4):979-1005.

Kelana, P.P., Setyobudiandi, I., Krisanti , M. 2015. Kondisi habitat dan polymesoda erosa pada kawasan ekosistem mangrove cagar alam leuweung sancang. Jurnal Akuatika. 6(2):107117.

Keputusan Menteri Negara Lingkungan Hidup. 2004. Nomor 201 Tahun 2004: Kriteria Baku dan Pedoman Penentuan Kerusakan Mangrove. Jakarta. Indonesia.

Kittamura, S., Anwar, C., Chaniago, A., dan Baba, S. 2003. Buku Panduan Mngrove di Indonesia. Internasional Society for Mangrove Ecocystem (ISME). Denpasar. Indonesia.

Lalo, A. 2003. Kajian Ekologi Ekonomi dalam pengelolaan ekosistem mangrove secara lestari di kawasan pesisir banawa selatan kabupaten Donggala. Bogor. Institut Pertanian Bogor.

Mughofar, A., Masykuri, M., \& Setyono, P. 2018. Zonasi dan komposisi vegetasi hutan mangrove Pantai Cengkrong Desa Karanggandu Kabupaten Trenggalek Provinsi Jawa Timur. Jurnal Pengelolaan Sumberdaya Alam dan Lingkungan. 8(1):77-85.
Natividad, E.M.C., Vivian, S., Hingabay, Harold, B., Lipae, Elani, A., Requieron, Abalunan, A.J., Paolo, M., Tagaloguin, Remedios, S., Flamiano, Jess, H., Jumawan, dan Joycelyn, C. 2015. Vegetation analysis and community structure of mangroves in Alabel and Maasim Sarangani Province, Philippines. ARPN Journal of Agricultural and Biological Science. 10(3):97-103.

Nursal, Yuslim, F., Ismiati. 2005. Struktur dan komposisi mangrove Tanjung Sekodi Kabupaten Bengkalis Riau. Jurnal Biogenesis. 2(1):1-7.

Petra, J.L., Sastrawibawa, S., dan Riyantini, I. 2012. Pengaruh kerapatan mangrove terhadap laju sedimen transpor di pantai Karangsong Kabupaten Indramayu. Jurnal Perikanan dan Kelautan. 3(3):329-337.

Poedjirahajoe, E., Marsono, D., dan Wardhani, F.K. 2017. Penggunaan principal component analysis dalam distribusi spasial vegetasi mangrove di Pantai Utara Pemalang. Jurnal Ilmu Kehutanan. 11:29-42.

Pramudji. 2000. Hutan mangrove di Indonesia: peranan permasalahan dan pengelolaannya. Oseana. XXV (1):13-20.

Prayudha, E.D., Sulardiono, B., dan Hendrarto, B. 2014. Srategi kelompok Pantai Lestari dalam pengembangan kegiatan rehabilitasi mangrove di Desa Karangsong Kabupaten Indramayu. Management of Aquatic Resources. 3(3):8087.

Prihadi, D.J., Riyantini, I., dan Ismail, M.R. 2018. Pengelolaan kondisi kosistem mangrove dan daya dukung lingkungan kawasan wisata bahari mangrove di Karangsong Indramayu. Jurnal kelautan nasional. 13(1):53-64.

Standar Nasional Indonesia. 2011. Survei dan Pemetaan Mangrove. Indonesia.

Susiana. 2017. Analisis kualitas air ekosistem mangrove di Estuari Perancak Bali. Jurnal Ilmiah Agribisnis dan Perikanan. 8(1):42-49.

Usman, Laila., Syamsuddin., Hamzah, S.N., 2013. Analisis Vegetasi Mangrove di Pulau Dudepo Kecamatan ANggrek Kabupaten Gorontalo Utara. Jurnal Ilmiah Perikanan dan Kelautan. 1(1):11-17.

Wantasen, A.S. 2013. Kondisi kualitas perairan dan substrat dasar sebagai faktor pendukung aktivitas pertumbuhan mangrove di pantai pesisir Desa Basaan I, Kabupaten Minahasa Tenggara. Jurnal Ilmiah Platax. 1(4):204-209. 